\title{
O FEEDBACK CORRETIVO ORAL EM PARES PARA A PRODUÇÃO TEXTUAL ESCRITA NO TELETANDEM INSTITUCIONAL- INTEGRADO
}

\section{PEER ORAL CORRECTIVE FEEDBACK FOR WRITTEN PRODUCTION IN THE INSTITUTIONAL-INTEGRATED TELETANDEM}

Rubia Mara Bragagnollo'

\begin{abstract}
RESUMO: O presente artigo trata do processo de feedback corretivo em pares para a produçấo textual escrita na modalidade do Teletandem Institucional-Integrado (TTDii), em uma turma de Português Língua Estrangeira (PLE) de uma universidade do sul dos Estados Unidos. Uma das atividades requeridas no TTDii, além dos encontros realizados virtualmente pelo Skype® para a aprendizagem de línguas, é a produçáo de textos para a prática da escrita na língua-alvo do aluno. Há um processo de escrita colaborativa caracterizado pelas açóes de a) escrita; b) envio ao parceiro para correçáo por escrito; c) feedback corretivo oral na sessăo de TTDii seguinte; d) reescrita dos textos. O objetivo deste artigo é apresentar resultados relacionados ao feedback corretivo oral das sessóes de TTDii para produçóes textuais das participantes, a partir da análise dos episódios nos quais os alunos conversam sobre os textos corrigidos. A análise das gravaçōes de áudio e vídeo das sessōes de TTDii mostrou que o feedback oral foi benéfico, pois ofereceu oportunidades para que os parceiros esclarecessem dúvidas relativas à correçâo por escrito, obtivessem explicaçôes gramaticais e culturais da língua portuguesa, entre outras vantagens que sâo apresentadas neste estudo.
\end{abstract}

PALAVRAS-CHAVE: Escrita colaborativa; feedback corretivo oral; Teletandem InstitucionalIntegrado.

ABSTRACT: This paper deals with the peer corrective feedback for written production in the Institutional-Integrated Teletandem (iiTTD) in a Portuguese as a Foreign Language group of a southern university from the United States of America. One of the activities required in iiTTD, besides virtual meetings made by Skype $\circledast$ for language learning, is the production of compositions for the practice of writing in the students' target language. There is a collaborative writing process characterized by the actions of a) writing; $b$ ) sending to the partner for written correction; c) oral corrective feedback in the following iiTTD session; $d$ ) rewriting of the texts. The aim of this paper is to present results related to oral corrective feedback of TTDii sessions for textual productions of the participants, from the analysis of the episodes in which students discuss the corrected texts. The analysis of audio and video recordings of iiTTD sessions showed that oral feedback was beneficial because it offered opportunities for partners to clarify doubts regarding the

Professora Doutora de Língua Inglesa do Instituto Federal de Santa Catarina, campus Gaspar. E-mail: rubia.mara@ifsc.edu.br 
written correction, obtain grammatical and cultural explanations of the Portuguese language, among other advantages that are presented in this study.

KEYWORDS: Collaborative writing; oral corrective feedback; Institutional-Integrated Teletandem.

\section{INTRODUÇÃO}

O teletandem é um exemplo de contexto de aprendizagem de línguas que utiliza o computador e a Internet para proporcionar o contato entre alunos universitários seguindo-se os princípios do tandem, o qual, por sua vez, consiste em sessōes de interaçăo bilíngues, nas quais falantes de diferentes línguas têm o interesse em aprender a Língua Estrangeira (LE) na qual o outro é proficiente (VASSALLO \& TELLES, 2006)

Além de proporcionar a prática da língua-alvo dos participantes do teletandem, esse contexto ainda funciona como facilitador de contato intercultural online (KRAMSCH \& URYU, 2014). Segundo Telles (2015, p. 6), “o contato intercultural por meio do teletandem fornece aos alunos oportunidades de perceber e expressar as diferentes concepçôes culturais que cada um tem do seu país e do país do parceiro, ou ainda de um terceiro país". Nesse sentido, o teletandem representa náo apenas um contexto de aprendizagem de línguas, mas, também, de trocas culturais entre os participantes.

O teletandem teve início no Brasil por meio do Projeto Teletandem Brasil: línguas estrangeiras para todos (TELLES, 2006), um projeto que coloca alunos universitários brasileiros que querem aprender uma língua estrangeira em contato com alunos universitários de outros países que estăo aprendendo português, através de interaçōes por ferramentas como o Skype® e Oovoo®, utilizando-se de imagem, áudio e escrita, simultaneamente, com duraçăo média de uma hora (meia hora para cada língua). É um exemplo de contexto de aprendizagem virtual que conta com a colaboraçáo como um dos princípios, na qual um ajuda o outro na aprendizagem de LE. O projeto, atualmente, é desenvolvido nos campi de Assis, Sâo José do Rio Preto e Araraquara, da Universidade Estadual Paulista.

No contexto de aprendizagem em tandem, existe uma modalidade denominada Teletandem Institucional-Integrado (doravante TTDii), que teve início em 2011 e é reconhecida pelas instituiçóes de ensino envolvidas, fazendo parte de um curso de graduaçâo ou pós-graduaçăo. Nesse caso, a atividade de teletandem é incorporada à disciplina da LE em questăo e obrigatória aos alunos matriculados (ARANHA \& CAVALARI, 2014).

Uma das atividades que podem ser requeridas no TTDii, além da própria sessâo oral entre os alunos que ocorre via Skype®, é a produçăo de textos, como tarefa de casa sobre temas variados. A escrita é explorada a partir da exigência da produçáo de textos feita pelos professores das disciplinas nas quais as sessóes orais acontecem. Essa iniciativa leva em conta a importância de se praticar a modalidade escrita na aprendizagem de uma língua estrangeira e serve como um 'gatilho' para os assuntos da próxima sessâo. Assim, segundo Aranha \& Cavalari (2014), os textos produzidos no TTDii têm a funçáo de instigar assuntos para que as sessôes orais ocorram mais facilmente e para que haja um minimizaçāo de falta de assunto. 
A incorporaçâo da prática da escrita feita pelo TTDii foi uma adaptaçăo às necessidades do contexto. Sua prática, descrita detalhadamente por Cavalari \& Aranha (no prelo), ocorre entre a segunda e a sétima sessôes, nas quais os alunos devem trocar textos com seus parceiros estrangeiros, por meio de um revezamento entre produçáo em língua estrangeira (LE) e revisăo em língua materna (LM). Em cada semana, um dos membros do par interagente deve escrever um texto na língua alvo, com temas que sâo sugeridos pelos professores de acordo com o programa de sua disciplina, e enviar para o parceiro, que deverá corrigir o texto e enviá-lo de volta para que tal revisáo seja comentada na sessáo seguinte. Toda semana, a sessâo se inicia na língua na qual o texto foi escrito e o aprendiz daquela língua tem a oportunidade de solucionar suas dúvidas em relaçăo às revisōes e correçôes feitas pelo parceiro em seu texto (ARANHA \& CAVALARI, 2014). Essa sessăo, na qual os alunos conversam sobre o texto corrigido é o que chamo de feedback corretivo oral no TTDii. Espera-se que, idealmente, cada interagente escreva e reescreva os textos na língua alvo e também revise os textos de seu parceiro.

O objetivo deste artigo é investigar o processo de feedback corretivo oral no TTDii e abordar as possíveis implicaçóes desse feedback para produçôes textuais das participantes, a partir da análise dos episódios nos quais os alunos conversam sobre os textos corrigidos. $\mathrm{O}$ recorte feito neste artigo năo traz os textos em suas versōes originais e finais na íntegra, pois esse năo é o foco; no entanto, săo evidenciados trechos dos textos à medida que se faz conveniente mencioná-los para que auxiliem na compreensáo de como o feedback corretivo oral pode ter contribuído para a produçăo final dos textos no TTDii, ou seja, para a prática da escrita em si de alunas americanas, participantes deste estudo.

\section{PRESSUPOSTOS TEÓRICOS DO FEEDBACK CORRETIVO NA ESCRITA}

A escrita, tanto em língua materna quanto em língua estrangeira, deve ser ensinada e aprendida como um processo, o qual exige o cumprimento de algumas açóes, sendo a revisâo e a reescrita duas delas. Há vários trabalhos que abordam a revisăo e, consequentemente, a reescrita de textos, como, por exemplo, Sengupta (2000); Figueiredo (2001); Soares (2008), os quais foram levados em consideraçăo neste trabalho.

Revisar nâo é apenas corrigir os erros de um texto; a revisăo ajuda os alunos a refletir sobre a língua e a perceber a necessidade de tornar os seus textos mais claros (FIGUEIREDO, 2001) e ela pode acontecer năo apenas antes da reescrita, mas em qualquer momento da produçấo do texto. Para Faigley e Witte (1984, p. 107), por meio da revisăo, os alunos "podem descobrir o que exatamente eles têm a dizer e pensar sobre como leitores potenciais podem reagir ao seu texto".

A revisăo de textos é importante ao processo de escrita, pois por meio dela o escritor tem um feedback que proporciona a possibilidade de melhorar sua produçâo textual com relaçáo à língua e conteúdo, por exemplo e, consequentemente, colaborar com o desenvolvimento da língua alvo. Por isso, o erro náo deve ser considerado como algo negativo, que desestimula o aprendiz; pelo contrário, o erro, quando apontado e tratado como parte do processo de aprendizagem, funciona como uma oportunidade de evoluçăo na língua alvo em termos de nâo apenas adequar gramaticalmente o texto, mas, sobretudo, de atingir propósitos comunicativos específicos por meio da escrita. 
O feedback, entăo, é relevante à aprendizagem de línguas e, no caso específico dessa pesquisa, à escrita de textos, pois, segundo Shute (2007) ele desempenha um papel de apoio, o qual torna possível ao aluno realizar tarefas que ele náo conseguiria sem ajuda ou que teria dificuldades em fazê-lo sozinho.

A revisăo de um texto pode ser feita a partir de diversas formas de correçăo. Segundo Figueiredo (2001), as correçôes se dividem em dois tipos: a direta, realizada tradicionalmente pelo professor, que implica marcar no texto os erros e fornecer a forma correta, com maior ênfase nos aspectos formais; e a indireta, que tem por finalidade envolver os alunos no processo de correçâo, de modo a torná-los mais autônomos e reflexivos no processo de ensino-aprendizagem. Existem algumas maneiras de se realizar a correçấo indireta, de acordo com Figueiredo (2001): a autocorreçăo, a correçáo com a turma toda, conferências e a correçăo com os pares. Destaco a última, pois o contexto de trabalho desta pesquisa, o TTDii, propicia justamente a correçấo em pares, a qual será agora explicitada.

A correçâo em pares é sugerida por alguns autores (FIGUEIREDO, 2001; STORCH, 2007; DOBAO, 2012; SHEHADEH, 2010) por sua capacidade de proporcionar um tipo de aprendizagem colaborativa e caracteriza-se como um processo no qual os alunos leem os textos escritos por seus colegas e dâo sugestōes para melhorar a escrita. Além disso, esse tipo de correçâo estimula a comunicaçăo genuína, envolvendo os alunos na prática e negociaçâo de uma enorme gama de habilidades, como, por exemplo, a leitura e a discussăo (LEE, 1997). A escrita, assim, torna-se o foco da conversaçâo entre os alunos, sendo esse um dos pressupostos do TTDii, e é isso que ocorre nas sessóes do TTDii: após a revisáo dos textos realizada pelo parceiro, o tópico do encontro seguinte é baseado no texto escrito, a partir de comentários feitos pelo revisor, esclarecimentos de dúvidas sobre a correçăo realizada etc.

Segundo Dobao (2012, p. 41), "A análise da interaçáo entre pares como uma oportunidade de diálogo colaborativo revelou que, quando os alunos compartilham a responsabilidade do produto escrito ou oral, eles tendem a colaborar na soluçâo de seus problemas na língua" ${ }^{2}$. Ou seja, năo apenas contribuiçôes relativas aos textos podem ser dadas, como na aprendizagem da própria língua alvo do parceiro, no caso do TTDii.

Pesquisas acerca da correçâo em pares mostram que as interaçóes ocorridas nesse processo năo apenas facilitam a aprendizagem, mas também possibilitam aos alunos desempenhar diferentes papéis sociais, tais como: receber e dar conselhos, fazer perguntas e responder a elas, agir tanto como quem aprende quanto como quem ensina (JOHNSON, 1995; GOLDSTEIN \& CONRAD, 1990).

Na pesquisa de Storch (2007), a autora investiga os méritos do trabalho em pares na ediçâo de textos em aulas de língua estrangeira. Por meio de suas análises, a autora aponta vantagens dessa abordagem, chegando à conclusâo de que os aprendizes têm oportunidades de usar a língua-alvo para uma série de funçôes da escrita, inclusive para a aprendizagem de línguas em si. Seguindo a mesma linha de pensamento, Mendonça \& Johnson (1994) afirmam que "o feedback de pares tem efeitos positivos, já que as

The analysis of peer-peer interaction as an opportunity for collaborative dialogue has revealed that, when learners share responsibility for the written or oral product of the task at hand, they tend to collaborate in the solution of their language problems (Dobao, 2012, p. 41) - traduçâo nossa. 
sugestōes e explicaçóes oferecidas durante as avaliaçóes pelos pares permitiram aos alunos mostrar o que eles sabiam sobre a escrita e usar essa informaçăo em sua revisăo". 3

Rollinson (2005) aponta, também, uma lista com as maiores vantagens da estratégia de feedback em pares com relaçăo a cinco critérios: correçâo e revisâo, público-alvo, colaboraçăo, revisăo dos pares versus revisăo do professor, comunicaçăo e atitudes dos alunos. As vantagens destacadas por mim resumem-se em: a) os escritores revisam de forma eficaz seus textos com base nos comentários fornecidos pelos seus colegas; $b$ ) ser um leitor crítico da escrita dos outros pode tornar os alunos leitores mais críticos e revisores de sua própria escrita; c) comentários dos colegas podem encorajar um diálogo colaborativo, no qual o feedback bidirecional é estabelecido e o significado é negociado entre as duas partes - esse caso ocorre, especificamente, na modalidade do TTDii, já que além das correçôes nos textos, os alunos conversam sobre eles; d) quando os alunos veem o benefício de comentários dos colegas, suas atitudes em relaçâo a escrita se tornam mais positivas.

Além dessas vantagens apontadas por Rollinson (2005), O Institute for Writing and Rhetoric, da Darmouth College, expóe alguns fatos que justificariam a escolha de uma abordagem colaborativa no trato dos textos produzidos em língua estrangeira. Trago os principais a seguir:

Revisōes em pares ajudam os alunos a entender que eles năo estáo escrevendo para eles mesmos, mas, sim, para leitores reais; saber que seus pares lerăo seus textos dâo aos alunos um senso concreto para quem eles escrevem e por quê; a colaboraçáo oferece aos alunos a prática de analisar a escrita e encoraja-os a conversar sobre sua escrita, pois terăo de explicar certas escolhas de seus textos e até defendê-las; a colaboraçáo ajuda os alunos a compreender a escrita como um processo e aumentar o sentimento de domínio do que é, muitas vezes, uma tarefa complexa e difícil; a melhor maneira de aprender algo é ensinando-a, visto que, ao instruir seus pares, os alunos aprendem a melhorar a sua própria escrita. ${ }^{4}$

Vale ressaltar que, segundo Shehadeh (2010, p. 112), "para um maior benefício e maior efeito do feedback, ele deve ser realizado tanto na forma escrita, quanto na forma oral, pois pesquisas têm mostrado que o feedback explícito escrito junto ao feedback oral afeta significantemente o nível de precisâo na escrita dos alunos". ${ }^{5}$ Nesse sentido, as sessóes de TTDii representam a oportunidade de se ter um feedback oral que corrobora o feedback escrito realizado previamente.

Outro estudo que mostra a eficiência de sessôes de conversa em pares sobre produçôes textuais em LE é o de Tsui \& Ng (2000). Esses autores, em uma pesquisa sobre os benefícios das correçôes de textos em pares, observaram que:

$3 \quad$ Peer feedback has positive effects since the suggestions and explanations offered during the peer reviews allowed students to show what they knew about writing and to use that information in their revision (MENDONÇA \& JOHNSON, 1994, p. 765) - traduçâo nossa.

4 Página do Instituto com a lista completa de itens sobre o trabalho em pares: http://writingspeech.dartmouth.edu/teaching/first-year-writing-pedagogies-methods-design/collaborativelearninglearning-peers .

5 It is worth mentioning that for feedback to have an optimal effect and benefit, it must combine both written and oral feedback because research has shown that explicit written feedback together with conference (oral) feedback significantly affects the level of accuracy in the students' writing (SHEHADEH, 2010, p. 112) - traduçâo nossa. 
[...] os comentários escritos pelos pares funcionam melhor quando săo complementados por sessóes orais em pares nas quais os alunos têm a oportunidade de esclarecer o seu raciocínio, explicar seus significados pretendidos e, de forma colaborativa, explorar formas eficazes de expressar seus pensamentos e argumentos (TSUI \& NG, 2000, p. 168) .

Uma discussáo oral combinada com o feedback escrito é considerada importante pelos aprendizes, pois esse tipo de abordagem minimiza questôes mal entendidas e esclarece o feedback. Thorsteinsen (2010), em seu estudo sobre feedback escrito, mostra essa noçăo, já que os alunos e professores entrevistados pela pesquisadora afirmam preferir o feedback oral junto ao escrito para facilitar a compreensăo de aspectos que o feedback escrito sozinho náo deu conta. Logo, a proposta de se inserir o feedback oral como uma das atividades de TTDii, além de poder ser usada como gatilho para a conversa e como uma possível ferramenta para o caso de ausência de assunto, conforme Aranha \& Cavalari (2014) afirmam, também corrobora para o melhor funcionamento do feedback escrito.

Para finalizar o aporte teórico, faz-se relevante mencionar a questăo do aluno de cursos de licenciatura que faz TTDii, como é o caso da presente pesquisa, e que pode se utilizar dos momentos de fornecimento de feedback corretivo para colocar em prática seu conhecimento e adquirir experiências com o ensino e a aprendizagem de línguas. Fernandes \& Telles (2015) tratam desse tema, junto a um enfoque na forma durante as sessōes de teletandem, enfatizando esse contexto como oportunizador de práticas docentes para os professores em formaçăo que atuarăo (ou já atuam) na educaçăo. Assim, o feedback corretivo năo seria benéfico apenas para o aluno que o recebe, mas, também, para quem dá esse retorno, seja por escrito ou oralmente, durante as sessōes de TTDii.

\section{METODOLOGIA DA PESQUISA}

Esta pesquisa é caracterizada pela natureza interpretativista (LOPES-ROSSI, 2009), a qual permite ao pesquisador analisar o processo e interpretar a realidade, desenvolvendo conceitos, ideias e entendimentos a partir de padröes encontrados nos dados coletados, com uma atribuiçăo subjetiva à pesquisa. De base etnográfica (MOITA LOPES, 1994; MASON, 1998), o estudo também constitui-se pela abordagem qualitativa que, conforme Denzin e Lincoln (2006, p. 23), ressalta "a natureza socialmente construída da realidade, a íntima relaçăo entre o pesquisador e o que é estudado, e as limitaçôes situacionais que influenciam a investigaçăo".

O contexto estudado foi constituído por duas turmas de TTDii - universitárias americanas, alunas de português língua estrangeira, que interagiram com alunos brasileiros do curso de Letras da UNESP. A turma cujos dados foram coletados tinha doze alunas da graduaçăo da universidade americana de vários cursos (Majors), como Relaçōes Internacionais, Línguas Românicas, Negócios, Sistemas de Informaçāo, Bioquímica, regularmente matriculadas no curso de Português - Port 3010. A maioria das alunas estudava, na época, português como uma das disciplinas minoritárias (Minors) do seu curso e por diferentes motivos: algumas porque têm familiares que

$6 \quad$ This study also shows that written peer comments work better when they are supplemented by oral peer response sessions in which learners are given the opportunity to clarify their thinking, explain their intended meanings and collaboratively explore effective ways of expressing their thoughts and arguments (TSUI \& NG, 2000, p. 168) - traduçâo nossa. 
falam português; outras porque já falavam espanhol e achavam mais fácil aprender Português; outras porque simpatizam com a língua, com os brasileiros e querem conhecer o Brasil ou já conheceram o país; e outras que consideram a língua portuguesa importante para o mercado de trabalho em que irăo trabalhar futuramente.

As alunas, com idade média de 20 anos, săo, em sua maioria, do Estado onde a universidade americana está localizada e a classe econômica é basicamente média ou média alta. Das doze alunas, oito falavam ou estudavam espanhol simultaneamente ao português, sendo que duas sâo falantes nativas da língua.

Os dados focais analisados no presente artigo fazem parte de um banco de dados de TTDii, do campus da UNESP de Sáo José do Rio Preto, o qual foi descrito por Aranha et al. (2015). Foram gerados e coletados em uma universidade pública do sul dos Estados Unidos, durante o Doutorado Sanduíche, no segundo semestre de 2013, e surgiram a partir de um curso composto por nove aulas, elaborado por nós, dentro da disciplina de Literatura Brasileira, lecionada por outra professora, para ensinar presencialmente os gêneros sinopse de filmes e resenha de filmes a alunas americanas que participavam do TTDii com a universidade brasileira.

Com base nessas aulas, foi solicitado às alunas que escrevessem os textos em português com a delimitaçăo dos gêneros trabalhados em sala e propósitos comunicativos específicos, para que pudessem enviar a seus parceiros brasileiros para a correçăo. Os textos tiveram como temáticas dois filmes brasileiros que foram assistidos pelas americanas junto às aulas de gêneros textuais: Eu, tu, eles (2000), dirigido por Andrucha Waddington, e $O$ contador de histórias (2009), dirigido por Luiz Villaça.

Salientamos que, embora o foco do estudo da tese tenha sido a produçăo textual dos gêneros ensinados às alunas (BRAGAGNOLLO, 2016), neste artigo o foco é o feedback corretivo oral, dado pelos parceiros brasileiros às americanas, considerando a importância que a escrita tem para o TTDii e como a correçâo em pares e a possibilidade de se discutir oralmente os textos podem contribuir para tal prática na universidade.

Portanto, os dados focais resumem-se às gravaçóes das conversas nas quais os participantes conversaram sobre os textos escritos pelas americanas e corrigidos pelos brasileiros. Foram transcritas, conforme os critérios adaptados de Marcuschi (1986), e analisadas a terceira, quinta e sétima sessôes de TTDii de todas as oito realizadas pelas duplas, pois foram nessas sessôes que os alunos falaram sobre os textos das americanas.

O intuito da análise aqui apresentada é responder às seguintes perguntas de pesquisa: a) como os participantes de TTDii conversam sobre os textos corrigidos; b) quais săo as implicaçōes do feedback corretivo oral para a produçâo textual no TTDii. Trazemos dados e análise de algumas alunas, identificadas por nomes fictícios, e que foram consideradas como passíveis de fornecer informaçôes para responder às perguntas de pesquisa.

\section{ANÁLISE DOS DADOS: O FEEDBACK CORRETIVO ORAL EM FOCO}

A análise das sessóes de TTDii que abordam os textos produzidos pelas americanas foi feita a partir da observaçăo de características que permeiam as conversas dos participantes da pesquisa, a fim de compreender como se dá o feedback oral dos textos durante essas sessóes. Durante a análise das sessôes gravadas, dois aspectos pareceram relevantes para conhecer as dinâmicas do feedback corretivo e como os alunos 
abordam os textos de modo geral em busca de entender as possíveis implicaçōes para as produçôes textuais, quais sejam:

a) Ajustes conversacionais - uso da língua portuguesa e da língua inglesa nas sessóes;

b) Forma comoostextossáoabordadosnassessôes-superficialmenteoudetalhadamente.

Essas perspectivas foram selecionadas como momentos indicadores do potencial influenciador da atividade de TTDii na produçáo de texto das alunas americanas, pois a) auxiliam na compreensâo de como o uso da língua-alvo ou materna pode ser relevante para o feedback oral; b) fornecem informaçâo acerca do modo pelo qual os alunos abordam os textos nas sessóes no sentido da importância que é dada por eles para tal atividade.

Com o intuito de mostrar como ocorreram as correçóes das sessōes do corpus, apresentamos cada um dos aspectos selecionados, discutindo as implicaçôes das sessóes de TTDii para as produçóes textuais das americanas. A identificaçâo dos trechos transcritos aqui é feita logo abaixo de cada excerto da seguinte forma: Excerto (número), dupla do TTDii (sendo o primeiro nome o da americana) e data da sessâo analisada, conforme o exemplo: Excerto 2, Elisa e Tati, 16/10/13.

O uso da língua inglesa quando os parceiros estavam conversando sobre o texto escrito em português foi uma das observaçōes de destaque das sessōes. Em todas as sessóes, as duplas falaram sobre a correçâo do texto no momento designado à língua portuguesa - conforme sugerido por Aranha \& Cavalari (2014), no TTDii, a língua a ser falada depende da língua na qual o texto foi escrito. Embora a maior parte tenha utilizado somente a língua portuguesa para tal, algumas duplas fizeram o uso do inglês, principalmente para esclarecer alguma dúvida que a dupla já havia tentado solucionar em português.

A primeira dupla a exemplificar essa observaçăo é a de Elisa e Tati, em sua terceira sessăo, que aborda a resenha do filme Eu, tu, eles. As alunas começam a sessăo conversando em português, mas Elisa, a americana, insere comentários em inglês o tempo todo com o intuito de se comunicar de forma mais eficiente, o que, para ela, seria mais fácil. Porém, um fato bastante interessante é que, frente a uma dúvida que Tati teve sobre um aspecto do texto (linha 13), Elisa afirma que năo explicará naquele momento (linha 14), pois acha difícil fazê-lo em português (linha 16), conforme vemos no trecho:

T: ahm, eu ou, só fiz algumas correçōes assim às vezes de artigo, ou de verbo, e aí essa parte que tá em, amarelo é que eu nâo sei a história na verdade aí eu queria linkar uma coisa na outra, mas eu, eu náo sei, năo entendi muito bem, quais săo os fatos que acontecem nessa parte

E: ok, ahm, quando falamos no inglês, eu vou explicar

T: ah ok ((risos))

E: porque é difícil em português ((risos))

T: ok

(Excerto 1, Elisa e Tati, 16/10/13)

Entâo, quando chega o momento de trocar as línguas, logo no início da conversa em inglês, Elisa volta a falar da dúvida que Tati teve no texto para ter a oportunidade de explicar em sua língua materna (linha 58): 
E: ok, ahm, so can you explain that, the highlighted part of the essay?

T: oh, yes, actually ahm, this part I highlighted in yellow ahm, I didn't understand actually what happened in the story, so ahm, I didn't ahm, correct anything

E: ok, ahm, can I explain it and (incomp) what I was trying to say to you

T: ok

E: so, I was TRYING to say, eventually Osias e, and Zezino saw that Ciro and Darlene were, or I guess it's an 'are', are in love and accepted Ciro, but Ciro was, ahm, or Ciro wanted more e, and fought with Darlene because she did not want to go with him

T: uhum

E: Osias saw that Darlene loves the other man, and loves the other man, and as he loves her, he adopts like her children

T: ok, ahm, what I didn't ahm understand was this part ahm 'quer mais lutas com hum Darlene', maybe it's not 'quer mais', maybe ahm, he just ahm 'mas Ciro ahm briga com Darlene porque ela năo quer ir com ele'

E: ok, so, wait, can you type that?

T: yes ((digitando no texto))... ahm I'm trying to, to find a good way to write that, ahm, 'estâo no amor' ahm, is not a good way to ((tosse))... sorry

E: yeah, I mean, in English, in English we say 'in love', so it literally it would be like you know 'in love', but I don't (incomp)

T: estăo apaixonados

E: ok

(Excerto 2, Elisa e Tati, 16/10/13)

Após Tati explicar o que significou a parte destacada por ela no texto (linhas 59-60), Elisa pergunta se pode explicar sua intençăo no texto em inglês (linha 61) e, em seguida, inicia a explicaçâo (linha 63), a qual é entendida por Tati. Nesse caso, a língua inglesa foi utilizada para esclarecimento e também para uma dúvida gramatical (linhas 75-78), sendo esse um fato que auxiliou no entendimento de Tati sobre o que Elisa quis dizer em seu texto. A partir desse esclarecimento, feito em inglês, Tati pôde realizar a correçáo adequadamente e, assim, contribuir para o texto de Elisa, mesmo que no quesito da forma.

Alguns pontos merecem destaque nesse excerto da sessăo de Elisa e Tati. Um deles é o uso do chat para auxiliar no processo do feedback corretivo. Na linha 72, Elisa solicita à parceira que escreva no chat do Skype® o que está tentando dizer. A partir disso, Tati escreve o trecho que necessita de esclarecimento, pois a colocaçăo de Elisa no texto năo ficou clara, conforme vemos no trecho da primeira versâo da resenha de Eu, tu, eles: Eventualmente, Osias e Zezinho vêem que Ciro e Darlene estâo no amor e aceitam Ciro. Mas, Ciro quer mais e lutas com Darlene porque ela náo vai ir com ele.

$\mathrm{Na}$ versăo reescrita da resenha de Eu, tu, eles de Elisa, podemos observar que a alteraçăo foi feita conforme a dupla conversou na sessăo, o que reflete os efeitos positivos do feedback corretivo realizado na língua materna da americana: Osias e Zezinho vêem que Ciro e Darlene estáo apaixonados e aceitam o novo homem, mas Ciro briga 
com Darlene porque ela nâo quer ir com ele. Osias percebe que Darlene ama o outro homem, e tenta provar seu amor por ela adotando todas as suas crianças.

Pode-se dizer, entâo, que, além do uso do inglês para que Elisa pudesse entender ao que a brasileira se referia, o chat demonstrou-se relevante para a compreensáo. O chat representa uma ferramenta muito importante para o feedback corretivo - năo só em textos, mas em correçóes da própria fala do parceiro. Leone (2012), ao tratar da negociaçăo de significados com foco na forma e as correçóes que ocorrem no contexto do teletandem, afirma que

o bate-papo escrito pode ser solicitado a partir de uma incompreensăo e usado como uma estratégia para facilitar a comunicaçăo: ao escrever uma palavra que năo foi entendida devido à pronúncia ou ao escrever uma traduçáo de uma palavra, os interlocutores estăo usando uma código semiótico que faz com que a mensagem se torne permanente e acessível ao longo do tempo (LEONE, 2012, p. 57). ${ }^{7}$

A segunda dupla que exemplifica o uso da língua na sessăo de feedback oral é Sophie e Beatriz, que em duas sessôes usa o inglês em alguns momentos durante a hora na qual a língua a ser falada é o português. Diferentemente de Elisa e Tati, essa dupla mistura as duas línguas e um fato instigante é que o uso do inglês sempre parte da aluna americana, apesar de a brasileira estar fazendo questionamentos em português, conforme vemos no excerto abaixo, pertencente à primeira sessăo da dupla:

B: existe a palavra, mas, melhor 'além disso', ok? ahm, esse pedaço 'sim năo' eu năo entendi, 'os homens estăo com medo de perder Darlene, sim năo aceitam os outros homens em sua vida'... achou?

\section{S: aham, sorry, hold on, I need to see what I put for that originally, wait, it's not the same thing that I put?}

B: é, eu náo mudei, tá a mesma coisa ainda

S: ok

B: 'os homens estăo com medo de perder Darlene, sim năo aceitam os outros homens em sua vida', achou?

S: ok

B: o que você quis dizer aí, porque eu nâo consegui entender

S: ahm?

B: o que você quis dizer, eu năo entendi

S: ahm, what am I trying to say there?

B: yeah

S: ahm, hold on, I know this, ahm, I think I was saying, if they... yeah, the men were afraid of losing her, if they don't accept the other men in her life

B: ah, ok, entâo aqui nâo seria assim

(Excerto 3, Sophie e Beatriz, 11/09/13)

In the specific case of Teletandem communication, written chat can be prompted by non-comprehension and used as a strategy to facilitate communication: by writing a word that has not been understood due to pronunciation or writing a translation of the word, interlocutors use a semiotic code that makes the message permanent and accessible over time (LEONE, 2012, p. 57 - traduçāo nossa). 
Nos trechos em negrito (linhas 114-115, 124 e 126-127) marcamos o uso que Sophie faz do inglês para dialogar com Beatriz e tentar esclarecer a dúvida que surgiu com relaçấo ao uso de 'sim nâo', no lugar de 'se năo' (linhas 114, 124 e 126). No caso exposto, năo se pode dizer que Sophie apela para o inglês como uma segunda alternativa de tentar explicar o que Beatriz năo entende depois de ter tentado com o português, pois durante toda a conversa a americana fala em inglês, que é respondida pela brasileira sempre em português.

Com esse excerto, observa-se que o uso da língua materna, mesmo durante a conversa sobre o texto escrita na língua alvo, faz parte das dinâmicas de feedback corretivo das sessōes de TTDii e pode auxiliar nas negociaçōes de significado, ${ }^{8}$ as quais, por sua vez, podem contribuir diretamente com a melhoria do texto.

No que concerne ao uso da língua materna para o feedback corretivo, Figueiredo (2001) afirma que ele náo deve ser visto como um impedimento para a aprendizagem da língua estrangeira, mas sim como um andaime (scaffolding) utilizado pelos alunos para facilitar esse processo. Esse uso da língua inglesa feito pela parceira americana contribui para seu próprio entendimento sobre o que a brasileira quer dizer em suas correçôes, o que, por consequência, poderia colaborar com a produçáo textual no momento em que Sophie fosse reescrever seu texto.

No texto de Sophie, o esclarecimento do trecho nâo compreendido pela brasileira é feito de forma correspondente ao que a americana indicou: Além disso, os homens estâo com medo de perder Darlene, se nâo aceitam os outros homens em sua vida.

O terceiro exemplo é um caso curioso de uso de língua para conversar sobre o texto da dupla Kathrin e Joăo. A dupla, em sua primeira sessăo, começa a conversa em inglês, embora seja o momento de falar em português, e Kathrin, a americana, faz a leitura da sinopse do filme Eu, tu, eles em voz alta, conforme sugerido por seu parceiro. Logo após a leitura, Joáo sugere que ele comente erros que encontrar no texto, já que a correçăo do texto foi feita durante a sessăo e năo previamente, conforme Aranha \& Cavalari (2014) sugerem sobre o funcionamento das trocas e correçóes dos textos no TTDii. Quando ele inicia a fala sobre os erros, Kathrin sugere que ele comece a falar em português naquele momento, conforme vemos no excerto:

J: bom, entâo I think I can, ahm, read the sinopse and see look for some mistakes but (incomp) simple aspects I don't know, could be this way?

\section{$\mathrm{K}$ : uhum, you can speak Portuguese now if you want ((risos))}

J: ok, entăo vamos lá, Darlene está grávida DE um menino, năo com

(Excerto 4, Kathrin e João, 11/09/13)

Mesmo năo sendo sua língua materna, Kathrin teve a iniciativa de falar em português na hora em que Joăo ia começar a comentar os erros no texto dela (linha 56). Essa

Entende-se negociaçâo de significados no contexto do Teletandem como os acordos e negociaçôes que os parceiros fazem durante a sessâo para esclarecer dúvidas, obter confirmaçấo ou repetiçấo daquilo que năo entendem (GARCIA, 2010). 
atitude mostra, provavelmente, que a própria aprendiz da língua entende que falar sobre aspectos gramaticais é mais fácil e mais produtivo na língua alvo, pois demanda explicaçōes e exemplos que serâo mais bem compreendidos na língua em que o texto foi escrito, nesse caso no português.

Sobre essa questâo, Cavalari (2006) declara que, no contexto de ensino e aprendizagem de LE, “o falante nativo pode ser útil ao aprendiz enquanto 'informante' dos aspectos linguísticos, culturais etc., a serem dominados, ou seja, o aprendiz busca, no falante nativo, um padrâo de língua alvo que seja aceito pela comunidade na qual está inserido e que lhe sirva de modelo" (CAVALARI, 2006, p. 1889). Nesse caso de Kathrin e Joâo, os aspectos linguísticos săo o foco das correçôes e o parceiro brasileiro faz o papel de falante nativo que, supostamente, tem conhecimento suficiente para apresentar modelos na língua alvo da americana.

Pressupóe-se que os parceiros de fato conversem na língua na qual o texto está sendo corrigido ou comentado, nesse caso, em português. Contudo, o fato de a parceira americana interromper Joăo, quando ele estava falando em inglês, e ela mesma propor a troca de línguas chama a atençăo para a importância que o feedback oral na língua alvo provavelmente tem para ela.

Os exemplos trazidos aqui dizem respeito a situaçôes nas quais as americanas buscaram estratégias para facilitar seu entendimento acerca das correçóes feitas pelos brasileiros. Isso quer dizer que a escolha da língua a ser falada em determinados momentos da conversa é um aspecto significativo das sessóes para as produçóes textuais e pode contribuir com o resultado do texto corrigido pelo parceiro brasileiro.

Com relaçăo a maneira como os alunos abordam os textos, há três tipos de sessóes: 1) a conversa nas quais os alunos abordam o texto com profundidade e detalhamento dos erros e correçôes; 2) aquela em que os alunos apenas comentam brevemente sobre a qualidade do texto ou algum aspecto mais superficial, sem entrar em detalhes nas correçōes que o parceiro brasileiro fez; e 3) as sessōes nas quais os alunos năo comentam em momento algum sobre os textos. Nosso interesse, aqui, săo os dois primeiros tipos de sessấo, pois fazem parte do nosso corpus justamente por tratarem dos textos escritos pelas alunas americanas.

A maioria das sessóes que abordam os textos o faz de forma aprofundada. Apenas duas sessóes náo tratam dos textos de maneira detalhada, inclusive pela questáo do tempo que os interagentes conversam sobre o texto: a primeira sessăo de Fernanda e Maria, cujo tempo de conversa sobre a sinopse de Eu, tu, eles foi de 02 minutos e 34 segundos; e a segunda sessáo de Grace e Isadora, na qual a conversa sobre a sinopse de 0 contador de histórias durou 02 minutos e 03 segundos.

Grace e Isadora, na segunda sessăo, apenas comentam sobre a FEBEM, pois Grace, a americana, tem dúvida quanto à instituiçăo, como vemos no excerto abaixo:
I: e... você, você viu a correçâo que eu te mandei?
G: $\operatorname{sim}$
I: deu tempo de ver ((risos))
G: sim, obrigada 
I: imagina, alguma coisa que cê năo tenha entendido?

G: ehm, deixe-me ver, ahm... é, năo

I: năo?

G: ((risos))

I: ((risos))

G: eu acho que, deixa, ahm... eu năo sei como descrever ahm FEBEM

(Excerto 5, Grace e Isadora, 25/09/13)

A partir do questionamento de Grace, Isadora descreve brevemente o que é a FEBEM e a parceira confirma o entendimento da explicaçăo:

I: uhum

G: nâo sabia se foi uma escola ou instituiçâo entăo

I: uhum

G: porque eu acho que foi as duas

I: é na verdade é uma instituiçăo pra menores de dezoito anos que cometem algum crime, eles văo pra lá e eles meio que năo ficam só presos eles têm que aprender alguma coisa, trabalhar, alguma coisa do tipo

G: oh ok

I: é mais pra jovens mesmo pra ver se salva eles

(Excerto 6, Grace e Isadora, 25/09/13)

Esse pedido e a posterior explicaçăo sobre a FEBEM estăo relacionados a questóes culturais no TTDii. O fato de essa instituiçáo existir apenas no Brasil, com esse nome, faz com que a aluna americana nâo tenha conhecimento sobre isso, pois nâo faz parte de sua realidade.

Zakir (2015), ao tratar de cultura no teletandem, discorre acerca de definiçōes para esse termo que representa um importante aspecto para o presente contexto. Em uma das noçôes de cultura apresentada pela autora (cultura como filiaçáo a um grupo), o termo é compreendido como forma de pertencimento a determinada comunidade discursiva e está relacionado a uma questăo de identificaçăo com algum grupo. “Essa identificaçáo pode se dar de diferentes maneiras, tais como localizaçâo geográfica, visăo política, religiăo, vestuário, comida e assim por diante" (ZAKIR, 2015, p. 92, grifo meu).

Nesse sentido, houve uma negociaçăo de significados relativa ao conteúdo do texto, o que auxiliou a parceira americana com o entendimento de um aspecto que fazia parte de sua sinopse. Pode-se ver, no trecho a seguir, que a definiçăo de FEBEM aparece no texto de Grace depois do esclarecimento da sessāo: Na drama "O Contador de Histórias" nós somos apresentados a Roberto Carlos (Paulinho Mendes) que mora na FEBEM, que é um instituiçăo do governo pelos jovens. 
Destarte, questōes culturais também săo implicaçóes do feedback corretivo oral, das sessôes de TTDii, para os participantes, e podem corroborar com a aprendizagem de línguas em níveis que extrapolam a forma de um texto. Esse excerto mostra como língua e cultura estăo associadas ao processo de aprendizagem de línguas.

Segundo Consolo \& Furtoso (2015, p. 675), “Às vezes o feedback cultural é motivado pela ocorrência de características linguísticas, às vezes informaçōes culturais motivam o desenvolvimento da conversa a fim de discutir sobre a língua utilizada de acordo com elementos culturais". ${ }^{9}$ No caso da dúvida de Grace sobre a FEBEM, uma questáo linguística, de significado da palavra no contexto brasileiro, levou a informaçôes culturais, que dizem respeito a uma instituiçáo brasileira, desconhecida pela americana.

Como dito anteriormente, apenas duas duplas, em sessōes específicas, abordaram os textos em um tempo curto. As outras sessóes transcritas revelaram uma dedicaçăo maior aos textos, que é evidenciada, primeiramente, pela duraçăo das conversas - a mais curta é de 04 minutos e 18 segundos e a mais longa é de 27 minutos; e em segundo lugar, pelos conteúdos que sáo comentados pelas duplas, os quais abordam as correçôes feitas pelos brasileiros de forma detalhada.

Neste momento, trago alguns excertos da sessăo da dupla Paula e Alex, ocorrida no dia 25 de setembro de 2013 e que tem a maior duraçăo de todas as sessôes (27 minutos), para exemplificar a abordagem detalhada do texto que eles realizaram, a partir de alguns tópicos que foram tratados por eles.

P: ah, ok, obrigada, entâo, eu tenho uma pregunta, ahhh... ((pausa enquanto a IA parece estar lendo em seu texto à procura da dúvida))... ah sim, ah, só ahm muitos errores que eu tenho é de usar as, like, 'da, do, em'

A: aham... sim, sim... é, assim, tem muitas pessoas que, elas utilizam, é, você utilizou bastante ((comentário de barulho próximo ao computador da IA e risos dos interagentes))... assim, é, por exemplo em vez de escrever 'em uma' né elas colocam 'numa' ((escreve no chat)), faz uma ((faz gesto com as mâos abertas, aproximando-as, para ilustrar uma reduçăo da preposiçăo))...é

P: ah, ok ((repetindo o mesmo gesto com as máos do IB, como se tivesse entendido))... eu sei

A: mas assim tem gente que usa, mas eu acredito que... na escrita năo é muito recomendado, entăo assim se você for escrever, prefere-se que você escreva na forma, mesma coisa de por exemplo, você tá escrevendo aí eu vou colocar é, por exemplo, 'I'm writing...' ((digitando no chat)), pa pa pa, né, melhor, 'I am writing' ((digitando no chat também)), né... sem abreviaçōes, na verdade, năo é uma abreviaçăo mas é, năo é muito comum né, é melhor você escrever assim, separados ((faz o gesto com as măos, ilustrando uma separaçăo))

P: em uma ((também repete o gesto do IB de separaçâo))

(Excerto 7, Paula e Alex, 25/09/16)

Sometimes the cultural feedback is motivated by the occurrence of linguistic features, sometimes cultural information motivates the development of the conversation so as to discuss language used according to cultural elements (CONSOLO \& FURTOSO, 2015, p. 675) - traduçâo nossa. 
Alex faz uma explicaçăo detalhada a partir da dúvida de Paula sobre os apontamentos feitos no texto, relativos ao uso de preposiçóes (linhas 16-20), inclusive comparando seu uso na modalidade escrita e na falada da língua (linhas 22-27) e utilizando exemplos em língua inglesa (linhas 24-25).

Destaco o fato de Paula ter iniciado a conversa sobre seu texto a partir de uma dúvida que ela teve sobre um problema bastante corrigido por Alex em seu texto (o uso de preposiçóes), o que demonstra, possivelmente, uma atitude de interesse da americana em melhorar seu desempenho na língua portuguesa. Essa açâo pode estar relacionada ao fato de que Paula se sente confortável para tratar de seus erros com o parceiro, o que seria justificado pelos papéis sociais que ambos têm de alunos e aprendizes - e năo de um ser professor do outro.

Outra questăo intrigante do excerto é o uso de gestos que os parceiros fazem para explicar e entender a contraçấo da preposiçăo "em uma" que Paula escreveu em seu texto, o que só foi possível verificar devido à gravaçăo da imagem da webcam. Quando Alex faz o gesto com as mâos para demonstrar a uniăo da preposiçâo "de" com o artigo "uma" (linha 19), ele está complementando sua fala; Paula, por sua vez, repete o gesto (linha 21), dizendo que entendeu a explicaçăo do parceiro. Com esse exemplo, entấo, pode-se inferir que a imagem facilitou a compreensâo durante o feedback corretivo oral.

Telles (2009), em seu estudo acerca do uso da webcam para as sessôes de teletandem, apresenta algumas declaraçôes dos participantes da pesquisa. Segundo eles,

as imagens da webcam: (a) tornam as sessóes de teletandem mais interativas e dinâmicas; (b) fornecem acesso a reaçóes faciais e gestuais de seus parceiros para o que eles dizem; c) facilitam a compreensăo, fornecendo pistas visuais se eles estăo sendo compreendidos ou se o assunto da conversa é agradável; d) fornecem aos parceiros um sentido de autoconfiança e segurança em relaçăo à conversaçáo; e) permitem uma melhor coordenaçâo da tomada de turnos durante a conversaçáo (evitando sobreposiçáo de turnos de conversaçăo); f) proporcionam uma sensaçáo de proximidade e intimidade. Os alunos também têm relatado que o teletandem sem imagens de webcam deixam a conversa meramente técnica, eletrônica, artificial, impessoal, e se assemelha à conversa telefônica (distante) ${ }^{10}$ (TELLES, 2009, p. 71)

No caso da dupla Paula e Alex, o gesto feito pelo brasileiro diz respeito ao fato de que isso tornaria a sessâo mais interativa, possibilitando a visualizaçâo de uma explicaçâo oral. Na continuaçâo da conversa sobre o mesmo tópico, Alex dá mais exemplos do uso de preposiçóes que Paula fez no texto e, em seguida, eles terminam esse assunto com comentários da americana que revelam seu entendimento, bem como a realizaçâo de gestos de ambos os alunos como forma de ilustrar a junçâo e a separaçấo das preposiçōes.

10 (...) students believe that webcam images: (a) make teletandem sessions more interactive and dynamic; (b) provide access to facial and gesture reactions of their partners to what they say; (c) facilitate comprehension by providing visual cues whether they are being understood or whether the conversation topic is enjoyable; (d) provide partners with a sense of self-confidence and security in regards to conversation; (e) allow a better coordination of turn-taking during conversation (preventing overlapping of conversational turns); (f) provide a sense of proximity and intimacy. Students have also reported that teletandem without webcam images make conversation merely technical, electronic, artificial, impersonal, and resemble telephone conversation (distant) (TELLES, 2009, p. 71) - traduçâo nossa. 
Além do uso da webcam, com esse último excerto podemos ter uma ideia de quáo detalhada é a conversa da dupla sobre o texto produzido por Paula. $\mathrm{O}$ aluno brasileiro fornece várias explicaçōes e exemplos sobre os aspectos gramaticais que a parceira apresenta dificuldade e isso dá a impressăo de que ambos estăo bastante envolvidos na atividade de feedback corretivo oral.

Na sequência, os parceiros falam também da preposiçăo "do" e Alex apresenta vários exemplos para tentar esclarecer o uso de "de", "do" e "da" antes de nomes de países e de pessoas no português. $O$ excerto abaixo mostra os exemplos que o brasileiro dá com relaçâo ao uso da preposiçăo antes de países:

P: ok, sim sim, porque eu... às vezes eu nâo sei do Brasil e de Brasil, na verdade.

A: ah tá, do Brasil e de Brasil, tá, deixa eu ver um exemplo, é... por exemplo eu, se se eu vou aí, te visitar aí algum dia, né, chego na sua casa lá, bato na porta ((faz gesto de bater na porta))

P: ((risos)) ((faz gesto de acenar como se estivesse cumprimentando o IB))

A: aí, aí que eu falo "eu, eu vim... do... ou de Brasil?" ((digitando no chat))

P: ((pausa para ela pensar)) oi.. oi... ah, os duas os dois săo usados? você está, você está...?

A: nâo ((risos))

P: ah, é, eu vi... de Brasil?...

A: ahh... ((risos))

P: nâo??? ((risos))

A: ((acenando negativamente com a cabeça e rindo))

P: por quê??? ((risos))

A: hum, é é mais comum você falar "eu vim do Brasil" ((digitando no chat))

P: ah, ok, 'eu vim do Brasil'... entăo, entăo você usa 'de Brasil' ou năo usa?

A: ahm, 'de Brasil', 'de Brasil'... năo, acho que năo

P: eu acho que năo

(Excerto 8, Paula e Alex, 25/09/13)

Com esse trecho, ressalto o papel que Alex assume ao explicar o uso de preposiçóes à sua parceira por meio de exemplos e de forma dinâmica, com encenaçăo (linha 50), de modo a deixar o clima entre eles descontraído e confortável. Ele é aluno do curso de Letras da UNESP, ou seja, é um futuro professor, em formaçăo inicial, e as dinâmicas de parcerias nas quais um dos participantes está estudando para ser professor sāo intrigantes de ser analisadas sob o ponto de vista de como o feedback é geralmente dado por ele. Algumas pesquisas tratam desse tema (KFOURI-KANEOYA, 2008; VIEIRAABRAHÂO, 2010), e o artigo de Fernandes \& Telles (2015), cuja temática é o enfoque na forma e o desenvolvimento do professor de língua estrangeira no teletandem, discute essa questăo de modo a apresentar benefícios da prática de teletandem para os alunos dos cursos de Licenciatura. 
Os autores declaram que o teletandem, quando praticado durante o curso de Licenciatura em Letras, pode auxiliar na formaçáo do futuro professor de línguas para atuar em contextos de ensino e aprendizagem de línguas diversificados, instaurados pelo uso das novas tecnologias.

A participação dos alunos (professores em formaçăo) em interaçóes de teletandem como parte constituinte das aulas de prática de ensino permite que estes reflitam sobre sua prática docente diante das novas realidades dos contextos de ensino à distância e sobre as competências que lhes săo necessárias para a atuaçăo nesses contextos. Assim, além de terem a chance de melhorar seus níveis de proficiência na língua estrangeira que văo ensinar, os futuros professores constroem sua própria prática (FERNANDES \& TELLES, 2015).

As açōes de Alex podem ser comparadas a de um professor, que leva o aluno a refletir sobre as informaçōes e auxilia no processo de construçăo do conhecimento. Quando ele faz a pergunta sobre como seria a forma correta de dizer "de Brasil" ou "do Brasil" (linha 52), e ainda digita no chat para complementar sua fala, ele faz referência a uma prática pedagógica, de quem de fato está querendo ensinar algo a alguém. Além disso, a inclusáo de vários exemplos, năo apenas nesse excerto, mas em toda a conversa, representa a presença de uma postura pedagógica, que pode vir a fazer parte de sua prática como docente futuramente.

A sequência desse trecho acima é caracterizada por mais exemplos para explicar a questăo do uso da preposiçấo "de" ou "da / do" antes de países e antes de nomes. Após essa discussăo, Paula afirma que percebeu que teve vários erros seu texto e cita o exemplo do verbo "converter", como na frase "ele se converte num rapaz 'irrecuperável"'. Alex esclarece, entăo, que o verbo está correto, porém năo é muito adequado para o sentido de se tornar, dando exemplos para essa questăo, como vemos no excerto abaixo:

P: e, que más... náo sei... é... wait what... ((pausa enquanto a americana está lendo seu texto corrigido e procurando por mais dúvidas)). ohh, convert... conver... ahm, converte... esta palavra, essa palavra é usado no Brasil ou náo?

A: deixa eu ver onde que tá

P: năo... converte

A: sim, sim, é utilizada, mas em alguns contextos em alguns casos, por exemplo...

P: ah, ok, sim, porque eu, ahm, eu esqueci dessa palavra ((risos)), entăo eu fui no google translate, pesquisei por 'transform', mas eu...

A: sim, é... de imediatamente assim vem dois exemplos na minha mente, né, de uso de converter... o primeiro é pode ser por exemplo quando você converte é, na linguagem da informática mesmo, quando você converte um arquivo, converte um vídeo, sabe, quando você transforma em AVI para MP3, MP4 ((risos))

P: ahm... ((risos))

A: pra... sim, esse é um uso que eu consigo identificar, e o outro envolve religiăo, quando uma pessoa se converte para outra religiăo

P: ok, entăo, é usado como aqui nos Estados Unidos

A: aham

(Excerto 9, Paula e Alex, 25/09/13) 
Observa-se, com o excerto acima, que é dada uma explicaçăo sobre uma palavra usada por Paula a partir de usos em determinados contextos, na língua portuguesa, os quais sâo identificados pela americana como recorrentes na língua inglesa também (linha 125). Sobre essa açâo de contextualizar uma palavra com seu uso, Long (1991 apud FERNANDES \& TELLES, 2015, p. 266) declara que o enfoque na forma pressupóe "um ensino que integra forma e significado dentro de um contexto comunicativo". Fernandes \& Telles (2015) utilizam essa citaçăo de Long (1991) para justificar a crença de que, no teletandem, a noçăo de forma tradicional é extrapolada, justamente porque leva em consideraçăo aspectos contextuais.

Da mesma forma que os autores, em sua pesquisa, observam que "a atençấo à forma envolve năo apenas o focalizar a estrutura da língua no nível morfossintático, mas também o enfoque no significado, ao tratar do léxico da língua dentro de determinadas estruturas linguísticas" (FERNANDES \& TELLES, 2015, p. 266), verifica-se essa constataçăo na conversa de Alex e Paula, quando a palavra "converter" é contextualizada dentro de estruturas linguísticas específicas - linhas 120-121: "converte um vídeo, sabe, quando você transforma em AVI para MP3, MP4" e linhas 123-124: "quando uma pessoa se converte para outra religiāo".

Quando Paula afirma que os usos de "converter" associados à conversâo de arquivos e à religiâo, conforme explicado por Alex, sâo os mesmos dos Estados Unidos, ela está fazendo relaçôes com a língua inglesa e como essa palavra é usada nessa língua também, o que reflete no entendimento que a americana teve a partir da explicaçăo do parceiro.

Ao notar os erros de Paula, verificamos que muitos deles săo decorrentes da influência que a língua espanhola tem para a americana, já que essa é sua língua materna - seus pais sâo mexicanos. Trago um excerto que aborda a confusăo que Paula tem em relaçâo ao espanhol e que é identificada por ela mesma.

P: sim, sim, às vezes eu tenho ahm... dúvidas de se, a palavra é feminina ou masculina, porque em espanhol eu sei as palavras que são femininas e masculinas, mas em português, ah pode ser diferente

A: pode ser por exemplo, 'viagem', 'el viaje'

P: ah, é... ((risos))

A: é, 'yo hizo una viaje' ou or 'um viaje'? ((risos))

P: UN viaje ((risos))

A: un viaje! ((risos)) but in Portuguese we say ‘eu fiz UMA viagem'.

P: uma viagem, sim! por eso, si por eso eu tenho dificuldades

(Excerto 10, Paula e Alex, 25/09/13)

Entende-se que, por serem línguas "genética e tipologicamente próximas" (RAMOS et al., 2013), a influência do espanhol para o português (e vice-versa) é bastante comum tanto na oralidade quanto na escrita. Ocorre, assim, o que se chama de "interlíngua", quando há transferências linguísticas, e nesse caso Paula faz transferências do espanhol para o português. 
Depreende-se, com o exemplo de usos linguísticos diferentes e semelhantes no espanhol e no português, que TTDii é um contexto propício para a comparaçáo entre as línguas que pode ser considerado positivo para o entendimento da língua que o participante está aprendendo. Além disso, embora o princípio de separaçăo de línguas proposto pelo TTDii năo esteja sendo seguido, já que há uma mistura de inglês, português e espanhol, podemos observar, neste caso, o uso de mais de uma língua foi intencional para que houvesse uma maior compreensăo dessa questăo linguística presente no texto da americana.

Percebemos que, a partir de questōes pontuais do texto de Paula, os parceiros fazem do feedback oral um momento nâo apenas para esclarecer aspectos do próprio texto, mas para que elementos da língua portuguesa, relacionados àqueles que foram corrigidos no texto (como preposiçōes, verbos, substantivos), fossem explicitados e melhor entendidos pela americana.

Pela descriçâo dos assuntos comentados pelos parceiros, verifica-se uma abordagem minuciosa do texto, que inclui uma série de aspectos corrigidos pelo brasileiro. A fim de reforçar a ideia de que o feedback corretivo oral pode contribuir para as produçôes textuais das alunas, retomo Shehadeh (2010), que defende a inclusâo da oralidade nas correçôes de texto junto à correçâo feita por escrito, pois pesquisas têm mostrado que o feedback explícito escrito junto ao feedback oral afeta significantemente o nível de precisăo na escrita dos alunos.

\section{CONSIDERAÇÕES FINAIS}

Pretendemos, com esse artigo, discutir sobre o feedback corretivo oral, uma questâo relevante para a produçâo textual no Teletandem Institucional-Integrado e que demanda estudos por ser a escrita uma prática nova dentro do contexto do teletandem. Nosso objetivo foi mostrar dados que evidenciam a ideia de que muitos sâo os aspectos pertencentes ao processo de correçấo em pares e à interaçáo entre os alunos do TTDii quando da discussâo sobre os textos corrigidos pelos parceiros.

A partir da análise dos dados, que buscou responder às perguntas de pesquisa sobre o funcionamento do feedback corretivo oral no TTDii e suas implicaçóes para a produçâo textual em tal modalidade, foram identificados alguns possíveis impactos do feedback oral das sessóes de TTDii para as produçóes escritas das alunas, quais sejam: a) oportunidade que as americanas têm para buscar estratégias que facilitem seu entendimento acerca das correçôes feitas pelos brasileiros; b) a escolha da língua a ser falada em determinados momentos da conversa com o intuito de facilitar o processo do feedback corretivo oral; c) o tratamento de aspectos gramaticais, significados de palavras, pronúncia, os quais auxiliam em aspectos relativos à forma e ao conteúdo da língua; d) benefícios que o TTDii proporciona aos participantes por meio de ferramentas como a webcam e o chat; e) compartilhamento de ideias e explicaçăo de questôes sociais e culturais que fazem parte dos textos; f) oportunidade de práticas docentes para os futuros professores de cursos de licenciatura; g) elementos do texto que podem instigar a discussấo sobre outros aspectos linguísticos que o parceiro apresenta dificuldade.

Desse modo, acreditamos que o objetivo de investigar as implicaçôes e o papel do feedback corretivo para a produçấo de textos foi alcançado com sucesso, ao mesmo 
tempo em que foi evidenciada a necessidade de mais estudos acerca da escrita em Língua Estrangeira, em um ambiente virtual como o TTDii, e os processos inerentes à essa prática. Tais estudos podem corroborar com a aprendizagem de línguas de alunos universitários, bem como com sua formaçăo docente, nas práticas de ensino possibilitadas por essa recente modalidade. Além disso, os estudos sobre feedback corretivo oral em pares podem ser interessantes para que tal açăo esteja cada vez mais presente inclusive em outros ambientes de aprendizagem de línguas, como na sala de aula. 


\section{REFERÊNCIAS}

ARANHA, S; CAVARALI, S. M. S. A trajetória do projeto Teletandem Brasil: da modalidade institucional năo-integrada à institucional integrada. The ESPecialist. v. 35, n. 2, pp. 70-88, 2014.

. Institutional Integrated Teletandem: What have we been learning about writing and peer feedback? DELTA - Revista de Documentaçăo e Estudos em Linguística Teórica e Aplicada, v. 31(3), pp. 763-780, 2015.

ARANHA, S.; et al. A criaçâo de um banco de dados para pesquisas sobre aprendizagem via Teletandem Institucional Integrado (TTDii). Revista (Com)Textos Linguísticos, n. 9, v. 12, pp. 274-293, 2015.

BRAGAGNOLLO, R. M. Uma proposta de trabalho com gêneros textuais para os textos escritos no Teletandem Institucional-Integrado. Tese (Doutorado) - Programa de Pósgraduaçâo em Estudos Linguísticos, UNESP, Sāo José do Rio Preto, 2016.

CAVALARI, S. M. S. Opçôes e implicaçōes do gerenciamento do erro em aulas de língua estrangeira. Estudos Linguísticos XXXV, pp. 1887-1896, 2006.

CAVALARI, S. M. S.; ARANHA, S. Teletandem: integrating e-learning into the foreign language classroom. (no prelo).

CONSOLO, D. A.; FURTOSO V. B. Assessing oral profi ciency in computer-assisted foreign language learning: A study in the context of teletandem interactions. D.E.L.T.A., v. 31, n. 3, pp. 665-689, 2015.

DENZIN, N. K.; LINCOLN, Y. S. A disciplina e a prática da pesquisa qualitativa. In: (orgs.). 0 Planejamento da pesquisa qualitativa: teorias e abordagens. Porto Alegre: Artmed, 2006.

DOBAO, A. F. Collaborative writing tasks in the L2 classroom: Comparing group, pair, and individual work. Journal of Second Language Writing. v. 21, n. 1, pp. 40-58, 2012.

FAIGLEY, L.; WITTE, S. P. Measuring the effects of revisions on text structure. In: BEACH, R.; BRIDWELL, L. S. (Ed.). New Directions in Composition Research. New York: The Gilford Press, pp. 95-108, 1984.

FERNANDES, A. M.; TELLES, J. A. Teletandem: enfoque na forma e o desenvolvimento do professor de língua estrangeira. Revista de Estudos da Linguagem, Belo Horizonte, v.23, n.1, pp. 261-287, 2015.

FIGUEIREDO, F. J. Q. de. Correçăo com os pares: os efeitos do processo da correçăo dialogada na aprendizagem da escrita em língua inglesa. Tese (Doutorado) - Programa de PósGraduaçāo em Letras: Estudos Linguísticos, Universidade Federal de Minas Gerais, 2001.

GARCIA, D. N. de M. Teletandem: acordos e negociaçôes entre os pares. Tese (Doutorado) - UNESP (Săo José do Rio Preto). Programa de Pós-Graduaçâo em Estudos Linguísticos, Săo José do Rio Preto, SP, 2010.

GOLDSTEIN, L. M.; CONRAD, S. M. Student input and negotiation of meaning in ESL writing conferences. TESOL Quarterly, v. 24, n. 3, pp. 443-460, 1990. 
JOHNSON, K. E. Understanding Communication in the Classroom. New York: Cambridge University Press, 1995.

KFOURI-KANEOUYA, M. L. C. A formaçăo inicial de professoras de línguas para/em contexto mediado pelo computador (teletandem): um diálogo entre crenças, discurso e reflexăo profissional. Tese de doutorado. Săo José do Rio Preto, Universidade Estadual Paulista, IBILCE, 2008.

KRAMSCH, C.; URYU, M. Intercultural contact, hybridity, and third space. In: JACKSON, J. (Ed.) The Routledge Handbook of Language and Intercultural Communication. New York: Routledge, 2014, pp. 211-225.

LEE, I. Peer Reviews in a Hong Kong Tertiary Classroom. TESL Canada Journal/La Revue TESL du Canada, v. 15, n. 1, pp. 58-69, 1997.

LEONE, P. Leadership in multimodal computer-mediated second language communication for reciprocal learning. Journal of e-Learning and Knowledge Society, v.8, n.3, pp. 55-66, 2012.

LOPES-ROSSI, M. A. G. Tendências Atuais da Pesquisa em Linguística Aplicada. Anais do 5ํeminário de Pesquisas em Linguística Aplicada. SePLA. Taubaté: Unitau, 2009.

MARCUSCHI, L. A. Análise da conversaçăo. Sâo Paulo: Ática, 1986.

MASON, J. Qualitative Researching, London: SAGE Publications Ltd, 1998.

MENDONÇA, C.; JOHNSON, K. Peer review negotiations: Revision activities in ESL writing instruction. TESOL Quarterly, 28(4), pp-767, 1994.

MOITA LOPES, L. P. Pesquisa interpretativista em Lingüística Aplicada: a linguagem como condiçăo e soluçăo. D.E.L.T.A., v. 10, n. 2. Săo Paulo: PUC-SP, pp. 329-338, 1994.

RAMOS, K. A. H. P. et al. O ensino de português para hispanofalantes no contexto virtual do Teletandem. Portuguese Language Journal, v. 7, pp. 1-22, 2013.

ROLLINSON, P. Using peer feedback in the ESL writing class. ELT Journal, v. 59, 23-30, 2005.

SENGUPTA, S. An investigation into the effects of revision strategy instruction on L2 secondary school learners. System, v. 28, n. 1, pp. 97-113, 2000.

SHEHADEH, A. One-to-one and Group Feedback in the L2 Writing Classroom: Benefits and Classroom Implementation. In: ANDERSON, D.; COMBE, C. (Orgs.). Cultivating real writers. Higher Colleges of Technology, UAE, pp. 109-120, 2010.

SHUTE, V. Focus on formative feedback. ETS Research e Development. Princeton, NJ, March 2007. Disponível em: www.ets.org/Media/Research/pdf/RR-07-11.pdf . Acesso em: 20 mar. 2016.

SOARES, D. A. A revisăo colaborativa e a produçăo textual em língua inglesa: o ponto de vista do aprendiz. Cadernos do IL, Porto Alegre, n. 36, pp. 81-97, jun. 2008.

STORCH, N. Investigating the merits of pair work on a text editing task in ESL classes. Language Teaching Research, n. 11, v. 2, pp. 143-159, 2007.

TELLES, J. A. Teletandem Brasil: línguas estrangeiras para todos. Projeto de Pesquisa - Faculdade de Ciências e Letras de Assis, Departamento de Educaçâo, Universidade Estadual Paulista, 2006. 
. Do we really need a webcam? The uses that foreign language students make out of webcam images during teletandem sessions. Letras \& Letras, Uberlândia 25 (2), p. 6579, jul./dez. 2009.

Teletandem and Performativity. Revista Brasileira de Linguística Aplicada, Belo Horizonte, v. 15, n. 1, pp. 1-30, 2015.

THORSTEINSEN, L. An interview study of the usage of written feedback in English education: The students' and the teachers' points of view. English Thesis, Akademin för utbildning, kultur och kommunikation, 2010.

TSUI, A. B. M.; NG, M. Do secondary L2 writers benefit from peer comments? Journal of Second Language, v. 9, n. 2, pp. 147-170, 2000.

VASSALLO, M. L.; TELLES, J. A. Foreign language learning in-tandem: Theoretical principles and research perspectives. The ESPecialist, v. 25, n. 1, pp. 1-37, 2006.

VIEIRA-ABRAHÂO, M. H. Teletandem Brasil - línguas estrangeiras para todos: um espaço para a formaçăo de professores de línguas. In: BENEDETTI, A. M.; CONSOLO, D. A.; ___. (Orgs.). Pesquisas em ensino e aprendizagem no Teletandem Brasil: línguas estrangeiras para todos. Campinas: Pontes, pp. 219-242, 2010.

ZAKIR, M. de A. Cultura e $(\mathrm{m})$ telecolaboraçăo: uma análise de parcerias de teletandem institucional. Tese (Doutorado) - Programa de Pós-Graduaçâo em Estudos Linguísticos. Universidade Estadual Paulista (UNESP), Săo José do Rio Preto, 2015. 